\title{
Socio-Economic Brand "Carpathians" in the Context of Tourism Industry Development in Countries of Central and East Europe
}

\author{
Fedir Shandor \\ Uzhhorod National University (UNU), Uzhhorod, Ukraine
}

\begin{abstract}
Brand in terms of strategy is a way of relationships between the organization and its target groups, aimed at removing a priori existing conflict. Therefore, formation of a new socio-economic brand "Carpathians", which joins a mountain system in the eastern part of Central Europe, Ukraine, Hungary, Poland, Slovakia, Romania, Serbia, and Austria, will help create a new image of Carpathians and implementation of programs aimed at the increase of investment activities, building confidence to domestic producers and creating programs to attract tourists to the most profitable tourist areas, in particular.
\end{abstract}

Keywords: brands, traditional products, famous brand, successful export

\section{Introduction}

Brand is a set of concepts generalizing people's ideas about certain product, service, company, or person. It is widely used in marketing and advertising, but nevertheless, it is a financial concern. Brand could have its own name, symbol, or graphic image, which represents an economic object and is uniquely associated with it in the minds of consumers. There are several major interpretations of the brand:

- in terms of linguists - brand is a way to identify graphically the specific manufacturer's products;

- in terms of advertising - it is a name, term, sign, symbol, or any other characteristic, which clearly identifies products, service as different from other goods and services;

- in terms of strategy - it is a means of relationship between the organization and its target groups, aimed at removing a priori existing conflict.

\section{Presentation of the main material}

Actually, brand is a unique combination of brand values a consumer pays an additional cost for or just prefers to buy, often causes unique emotions. The difference between a trademark and a brand is: A trademark may have a high sales turnover and brand has a high income. Brand or trade mark is a commodity that can be bought and sold. The Business Week magazine together with the Interbrand company regularly evaluates brands. At the moment, the most expensive brands are Coca-Cola, Microsoft, and IBM.

There are two concepts "brand valuation" and "brand evaluation", which are translated identically—brand value, but they have fundamental differences: Brand valuation means "value of brand" and brand evaluation

Fedir Shandor, Ph.D. of philosophy and sociology, head of Tourism Sub-Department, Uzhhorod National University (UNU), Uzhhorod, Ukraine.

Correspondence concerning this article should be addressed to Fedir Shandor, Universytetska Street 14, Uzhhorod, Ukraine. E-mail: f.shandor@gmail.com. 
represents "cost of brand" (Smoliy \& Fedorchenko, 2006).

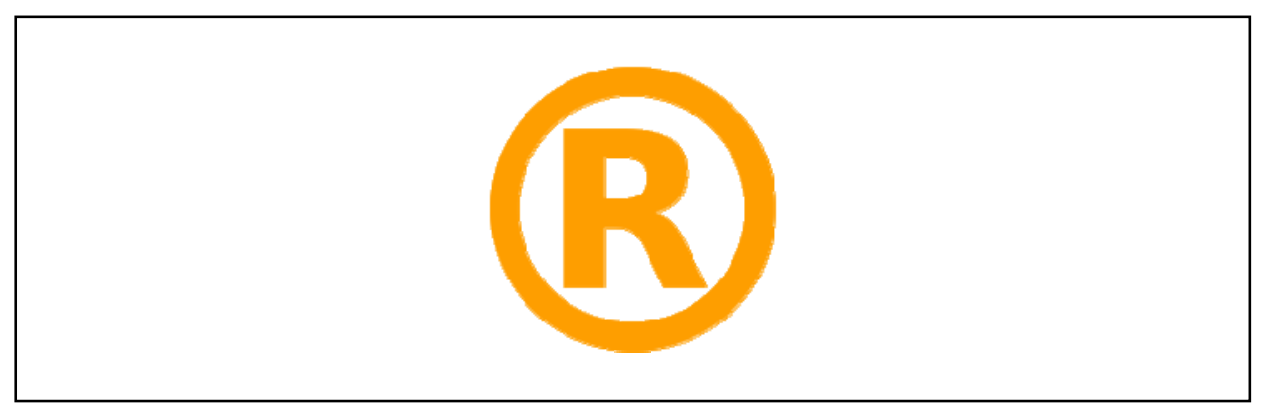

Figure 1. Traditional international symbol of the registered mark for goods and services.

This is a traditional international symbol of the registered mark for goods and services (Figure 1). The Latin letter R means that the mark has been registered. Labels for goods and services (English trademark) are a symbol, under which goods and services of one person are different from goods and services of others. These symbols can be words, numerals, figurative elements, and combinations of colors. In the Civil Code of Ukraine concerning the mark for goods and services, the term "trademark" is used. The term "trademark" is a direct borrowing from English. In fact, the terms "mark for goods and services" and "brand" have the same meaning and can be used as equivalents.

In Ukraine, as in most legislative systems of the former Soviet Union, the rights for the trademark come in after it has been registered in the appropriate public department. In Ukraine, the State Department of Intellectual Property (SDIP) has this right. Formally, SDIP is responsible for the entire process of mark registration. However, in practice, most of the executive functions of SDIP in Ukraine are performed by the state enterprise "Ukrainian Industrial Property Institute" more known as the Ukrpatent. This institution examines the applications to register objects of intellectual property. Brand is the subject of intellectual property, legally protected by the Civil Code and law of Ukraine "about protection of rights for goods and services marks", and also on international agreements signed by Ukraine, including the Madrid Agreement (Retrieved from http://www.legal.com.ua/document/kodeks/000003689-12.html).

Juridical and physical persons of the signatories to the Madrid Agreement or Protocol, may provide in all other member states of the Madrid system protection of their trademarks through the filing of applications for these marks at the International Bureau of World Intellectual Property Organization, which carries out such registration. The international trademark registration has the same effect as its registration statement, submitted to each of these countries following national procedures. In case there is a need to increase the number of countries, where the mark protection is provided, the applicant may make a statement on territorial expansion.

Nowadays, Europe promotes the brands like "Alps", "The Balkans", and "Pyrenees".

Therefore, the headway of the trademark "Carpathians" is in the direct economic- and social-political interest of every Carpathian country. To reach the goal, there should be a tight constant cooperation between state authorities, science, and business. Scientists have to analyze, propose new ideas, concepts, plans, strategies, and develop them. Accordingly, state organs should provide with legislative acts, permissions, certification, and standardization, and business should invest resources to get benefits. Then the evolutionary cycle starts to operate: Business investing money pays taxes, from which state authorities finance science, which again produces innovation, and so the movement, improvement goes on (Lukashevytch \& Shandor, 2008). 
Have a look at the geographical location of Carpathians (the Carpathian Mountains) (Figure 2), this mountain system is situated on the East of Central Europe, on the territory of Ukraine, Hungary, Poland, Slovakia, Romania, Serbia, and Austria. It is stretched out on 1,500 km, forming a convex arc that closes the Mid Danube plain. The biggest width is $430 \mathrm{~km}$. Carpathians are one of the main Europe's watersheds between the Baltic and the Black Sea. Orographically, the Carpathian chain is divided into West Carpathians, East Carpathians (a part of which are the so-called Ukrainian Carpathians), the Beskids, Southern Carpathians, Romanian Western Mountains, and Transylvanian plateau. Prevailing height of the Carpathians is 800-1,200 m, the highest point is Herlach in Tatras $(2,655 \mathrm{~m})$, and in Ukraine it is Hoverla $(2,061 \mathrm{~m})$.

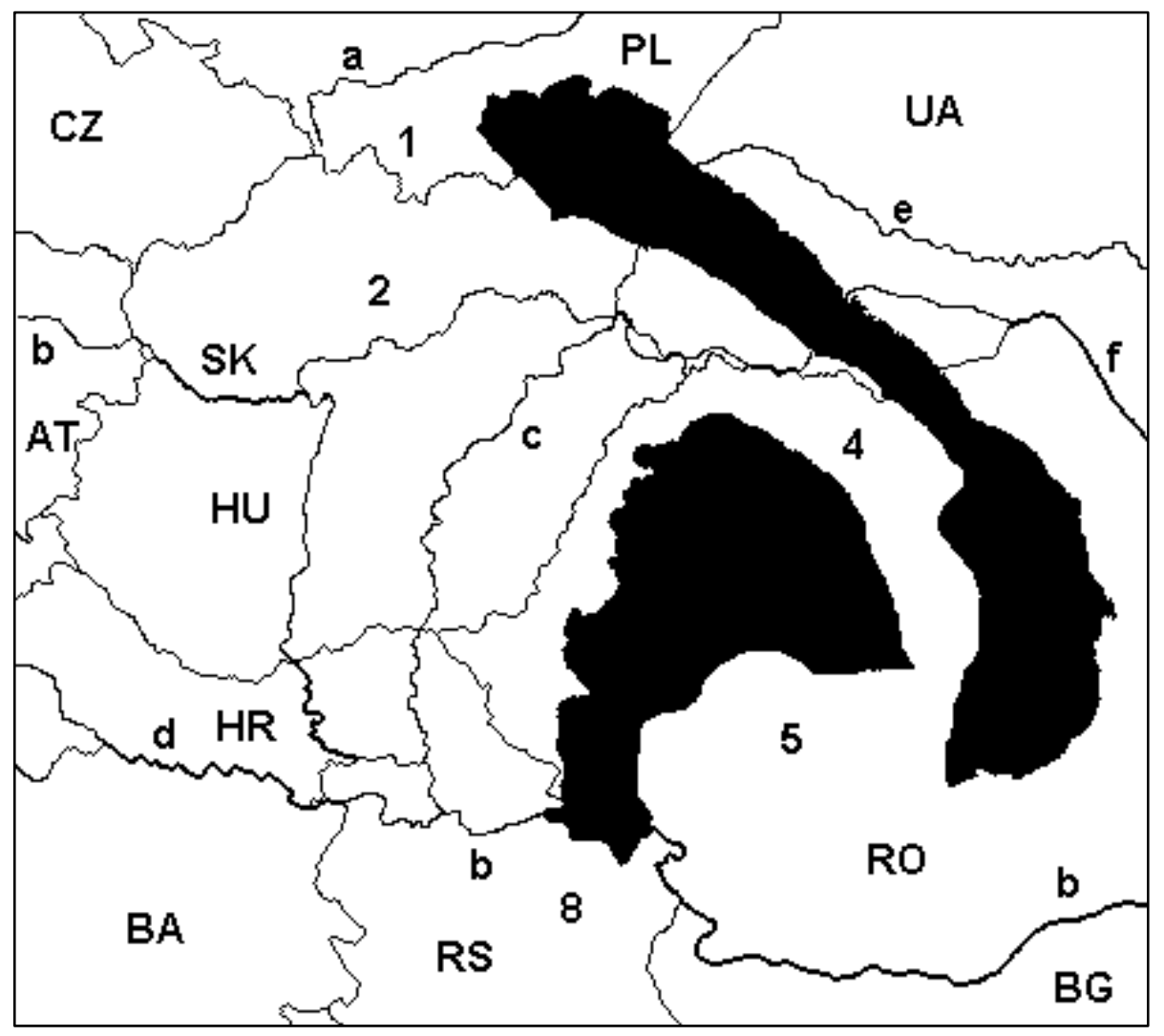

Figure 2. The geographical location of Carpathians.

In the next years, the tourist industry in the Carpathian Mountains can expect a considerable stir, because people's income decreased, and there will be a need to move from tourism for rich and upper-middle class to the middle and lower middle class. This class is a new economical base of the new European tourist brand "Carpathians": living in rural households, hostels, econom-class motels, which can provide relaxation on the principle of "decent quality-low prices" (Kvatralnov, 2002). New tourist routes are actively created in neighboring Carpathian countries with Ukraine. Nowadays, Slovakia, Czech Republic, Poland, Romania, Serbia, and Hungary are convinced on their own unsuccessful example that they have to care not only of their own tourist areas (owners of facilities in these areas not only of their objects), but cooperate together on the united brand-Carpathians (the Carpathian Mountains). Otherwise, this paper will have a replay of disappointing tourist facts in the Carpathians, when theorists of tourism industry predicted that the Slovakian Tatras could lose $40 \%$ of tourists during the winter season of 2008 to 2009, but the reality has proved a 
decrease of the tourist flow to about 76\%. From 20th of December to 12th of January, every day loss of this area made about 520 thousand euros. They have been dumped by the other brand "Alps" that has long ago united countries like France, Switzerland, Italy, Slovenia, and Austria. Today, the seasonal tourist potential of the brand "Carpathians" in the context of tourism development in Central and Eastern Europe makes about 10 million people (Ananyev, 1966). If the united brand "Carpathians" would not popularize, Carpathian countries would constantly lose marketing battles with such professionals as Alps, Mediterranean, Pyrenees, and Scandinavia.

\section{Conclusions}

Brand of the region should reflect all elements of uniqueness (Figure 3). The following scheme is provided as an example.

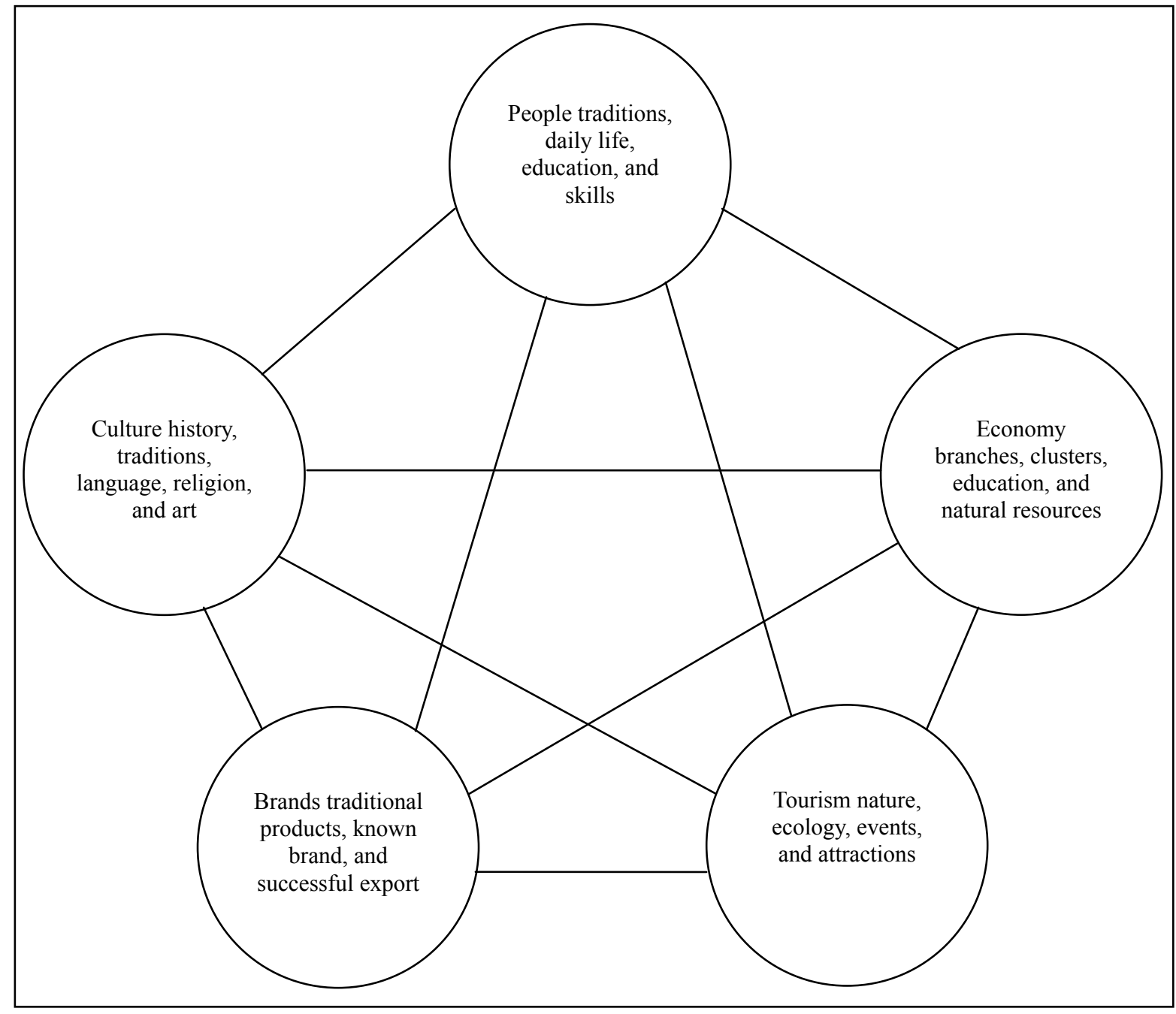

Figure 3. Brand of the region.

Target groups of branding of the Carpathian territories are:

- visitors of the area;

- companies and enterprises; 
- residents and employees on the territory;

- external markets.

Territorial tourism brand "Carpathians" has to form a clear regional idea: uniting of tourist business representatives, state authorities, educational institutions, professional associations from eight countries of the Carpathian region, which set up the following objectives:

- differentiate the Carpathian region in the total world tourist flow;

- create conditions to improve competitiveness of the Carpathian region on the tourist market;

- combine common tourist products and services into one network.

The place of a regional brand in the brand system on example of Transcarpathia/Zakarpattya is depicted in Figure 4.

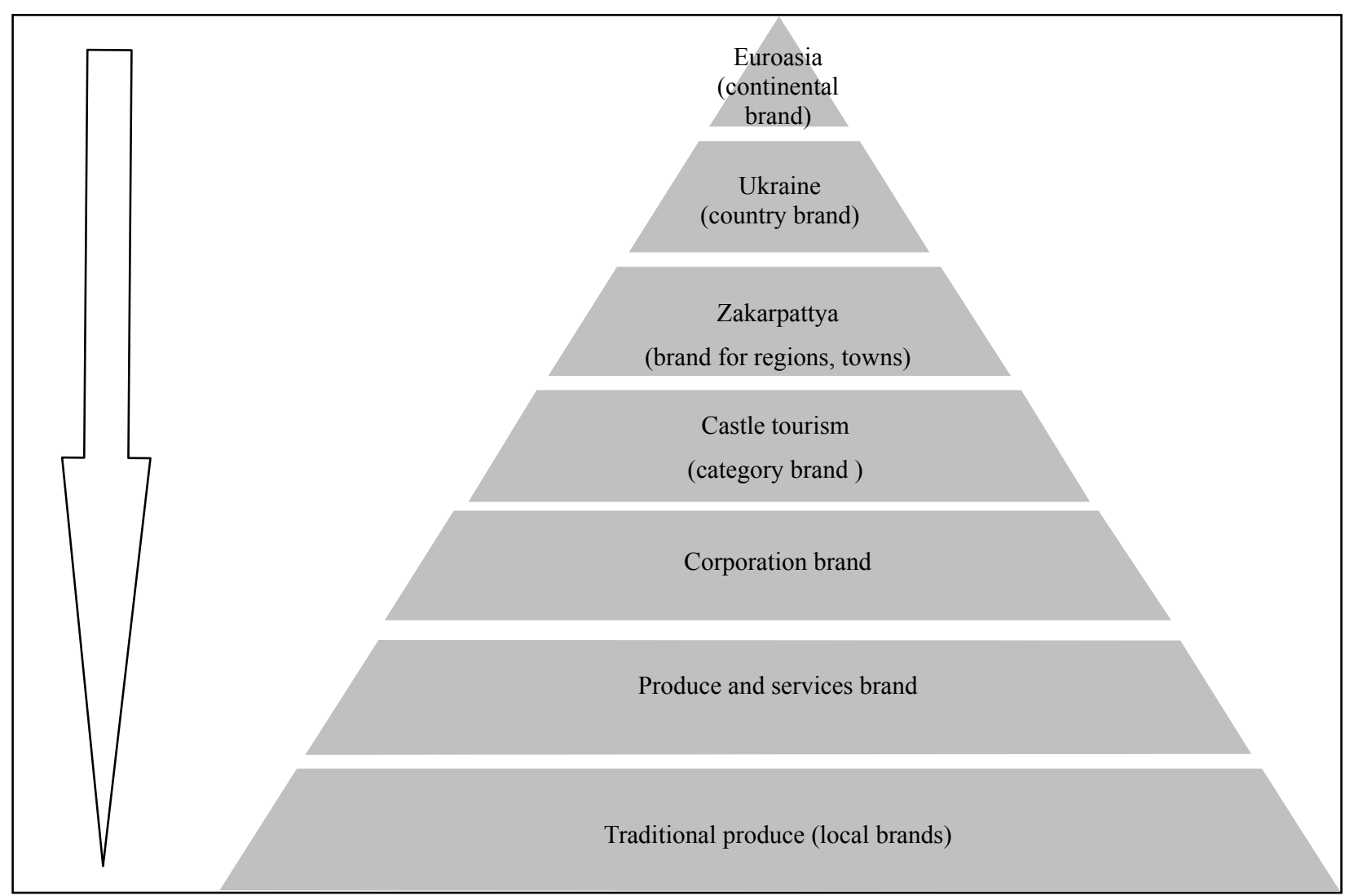

Figure 4. The place of a regional brand in the brand system on example of Transcarpathia/Zakarpattya.

General information about forming of a socio-economic tourist brand "Carpathians" in the context of tourism industry development in Central and Eastern Europe positioned four basic directions of the brand development in the Carpathian area:

- creating an image and implementing programs aimed at increasing of investment activities;

- building trust to national producers, comprehensive programs for promotion of national products abroad;

- creating an image of an attractive tourist destination and creating programs to attract tourists to the most profitable tourist areas;

- creating a program of an attractive image area. 


\section{References}

Ananyev, M. (1966). International tourism and its development after World War II. Moscow: Vneshtorhyzdat.

Kvatralnov, V. (2002). Biosphere and tourism: The global interaction and ecology, geographic scientific research of territories of tourist destination, world culture, tourist migration system, pedagogy, sociology and management strategy. Moscow: Nauka.

Law of Ukraine. (1993). Article 1 of the Law of Ukraine "on protection of marks for goods and services". Retrieved from http://www.legal.com.ua/document/kodeks/000003689-12.html

Lukashevytch, M., \& Shandor, F. (2008). Sociology of tourism. Uzhhorod: Art Line.

Smoliy, V., \& Fedorchenko, V. (2006). Encyclopaedic dictionary of tourism. Kyiv: Publishing House. 